Article

\title{
Doing Good Is Not Enough, You Should Have Been Authentic: Organizational Identification, Authentic Leadership and CSR
}

\author{
Byung-Jik Kim ${ }^{1}$, Mohammad Nurunnabi ${ }^{2,3, * \mathbb{B}}$, Tae-Hyun Kim ${ }^{4}$ and Taejoong Kim ${ }^{5, *(\mathbb{D})}$ \\ Sogang Business School, Sogang University, Seoul 04107, Korea; kimbj82@business.kaist.edu \\ 2 Department of Accounting, Prince Sultan University, PO Box 66833, Riyadh 11586, Saudi Arabia \\ 3 St Antony's College, University of Oxford, 62 Woodstock Road, Oxford OX2 6JF, UK \\ 4 College of Business, Korea Advanced Institute of Science and Technology, Seoul 02455, Korea; \\ taehyun@kaist.ac.kr \\ 5 College of Economics and Management, Chungnam National University, Daejeon 34134, Korea \\ * Correspondence: mohammad.nurunnabi@sant.ox.ac.uk or mnurunnabi@psu.edu.sa (M.N.); \\ tjkim006@cnu.ac.kr (T.K.); Tel.: +82-42-821-5553 (T.K.)
}

Received: 31 May 2018; Accepted: 13 June 2018; Published: 15 June 2018

\begin{abstract}
Previous studies on the relationship between corporate social responsibility (CSR) and organizational performance have emphasized how CSR influences the external stakeholders such as shareholders, customers, and local communities to explain the association. Thus, it is relatively less studied how CSR influences internal stakeholders, which ultimately accrue to organizational performance. Grounded on institutional theory which proposes that institutional enablers such as CSR activities affect macro-level outcomes (i.e., organizational performance) through micro-level mechanisms (i.e., attitudes or behaviors of members), we argue that internal processes are critical to explaining the CSR-performance link. Using 2-wave time-lagged survey data of 301 employees from various companies in South Korea, we first investigate how organizational identification (OI) mediates the CSR-performance link. In addition, we also investigate how authentic leadership moderates the link between CSR and OI. The results showed that OI is an important internal process that CSR enhances for organizational performance. In addition, authentic leadership positively moderated the effect of CSR on OI. Our results suggest that we need to understand "internal" intermediating mechanisms as well as critical contextual factors to elaborately explain the relationship.
\end{abstract}

Keywords: corporate social responsibility; organizational performance; micro-foundation; organizational identification; authentic leadership; moderated mediation model

\section{Introduction}

Corporate social responsibility (CSR) has received the considerable attention of both researchers and practitioners in business fields during recent decades [1-3]. Although some scholars have criticized CSR an inefficient use of organizational resource [4,5], many others have argued that CSR is a strategic resource to enhance the competitive advantage of firms $[1,6]$. Thus, they have examined the performance implication of CSR [7-13].

Although considerable studies on the CSR-performance link have been conducted, several issues remain unsolved. First, extant research on the relationship between CSR and organizational performance has found inconclusive results. For instance, some studies have demonstrated that CSR positively influences organizational performance $[6,7,10,14,15]$. However, the other has reported a non-significant or even a negative effect of CSR [5,16-18]. Some scholars suggest that the inconsistent results may originate in the lack of research that considers contextual moderating factors or mediators 
through which CSR affects organizational performance [15,19-21]. Thus, the mix of results calls for more attention on precise mechanisms that CSR affects organizational performance.

Another issue with current research on the CSR-performance link is that it has mainly focused on the effect of CSR on external stakeholders (i.e., shareholders, customers, and local communities) as a mechanism that CSR affects organizational performance [2,13]. For instance, Lai and his colleagues [10] reported that brand equity and corporate reputation function as mediators between CSR and organizational performance. Also, Saeidi and his colleagues [15] found that organizational reputation and customer satisfaction mediate the relationship between CSR and financial performance. Although this line of research contributed to expanding our understanding on the CSR-performance link, it is relatively underexplored how organizational internal stakeholders (i.e., employees) affect the relationship between CSR and organizational performance [1,3]. In fact, members of an organization are the ones who implement CSR practices [2]. Therefore, their attitudes and behaviors about CSR can be critical to determining the success or failure of the CSR practices [21-23]. This internally-oriented perspective may complement for the existing externally-oriented approach [24].

To resolve this debate and empirical inconsistency, in this paper, we integrate and extend two approaches (i.e., externally vs. internally-oriented) in the perspective of institutional theory and provide a more precise picture of the CSR-organizational performance relationship. The institutional theory suggests the importance of micro-level intermediary processes in the relationship between macro-level variables. For example, Scott [25] argues that institutional enablers (e.g., various practices, structures, or systems) affect organizational members' perception, attitude, and behavior that ultimately accrue to various institutional level outcomes such as financial performance [25]. Thus, we expect that CSR practices contribute to organizational performance by enhancing internal processes (i.e., attitudes of members).

To examine a micro-level underlying process between CSR and performance, we first focus on organizational identification (OI) because it is known as the root construct of an organization [26-28]. OI refers to the degree of awareness on how members identify themselves with their organization, and plays an important role in explaining their perception, attitudes, and behaviors [23-25]. By enhancing the quality of members' work attitudes [29,30] and behaviors [31,32], OI can contribute to organizational performance $[33,34]$. Considering both the institutional theory and extant studies on the relationships among CSR, OI, and performance, we propose that OI mediate the link between CSR and organizational performance.

Furthermore, we examine a contextual factor that influences the relationship between CSR and OI. In particular, we focus on the moderating role of authentic leadership (AL). AL is defined as a transparent and balanced decision-making pattern, based on a leader's internalized moral standards [35]. Given that members are likely to perceive their leader as a symbolic figure for an organization itself [36], they consider a leader's authenticity as an indicator to judge whether organizational policies, systems, and practices are genuine. Thus, if a leader is not perceived genuine, it may seed a doubt in the mindset of organizational members about the authenticity of CSR activities although the organization actively conducts CSR practices. For example, if a leader does not have authentic leadership, the followers may perceive that there is another true intention or hidden purpose in the CSR activities. This doubt of employees toward the authenticity of CSR activities would deteriorate the enhancing effect of CSR on OI. Considering that the authenticity of CSR practices plays an important role in fully actualizing the positive effect of the activities [37,38], we argue that AL can be a critical contingent factor that moderates the CSR-OI link.

Lastly, existing CSR and its related literature has constantly called for studies that consider diverse cultural contexts [22,24]. For instance, firms in developing countries such as Korea are likely to seek profit-maximization rather than morality or social responsibility, compared to developed countries such as USA, England, France, and Germany [24,39]. Considering that South Korea has experienced rapid economic growth over the past centuries, it is possible that Korean firms are relatively insensible to the issue of CSR. Therefore, we can raise a question whether the pattern of CSR's impact on performance 
in Korean firms is different with the firms in developed countries. As an adequate response to it, we expect that Korea can be an appropriate context for investigating the impacts of CSR activities.

\section{Theories and Hypotheses}

\subsection{CSR and OI}

To examine the internal mechanisms of CSR, we focus on employee's attitudes, OI which plays an important role in explaining the perception, attitudes, and behaviors of members, functioning as a "root construct" in an organization [26]. It is closely associated with the concept of identity and identification of individual members. "Identity" explains who a person is and why the person works in a certain organization, while "identification" is a process of establishing such identity toward a certain subject/context. Through "identification" with an organization, an individual gradually establishes his or her "identity" within the context of an organization [40].

The effect of CSR on OI can be explained by the following theoretical perspectives. The most typical approaches are social identity theory [26] and perceived external prestige (PEP) theory [41]. First, social identity theory has suggested that an individual's self tend to be influenced by the group that he or she belongs to. "Social self" means a kind of self which is formed by the influence. Because the organization is importance among groups that the individual belongs to, the organization is posited in the core of the individual's social self, that in turn impacts the individual's self-concept [42] (Pratt. When employees perceive that their company conducts CSR practices well, they are likely to believe that they are in an organization with a good reputation in society and build a positive social self. Considering that the firm has helped them gain an enhanced self, employees have bigger attachments to their firm, which facilitates the identification with their organization [42,43].

Second, PEP theory also supports that perceived CSR will enhance the OI of members. PEP means the employees' thoughts on how outside people will evaluate the organization they belong to [38]. This does not indicate how employees judge their own firm by themselves, instead, it indicates employees" "belief" about how their firm is perceived by the outside. This concept is known as "construed external image" [43], or "perceived organizational prestige of a perceived organization", etc. [31]. According to PEP theory, employees' OI is likely to be shaped by the perception of how outsiders evaluate the firm. Since the firm is critical to them, the external awareness on their firm has a huge impact on their self-esteem, self-confidence, or self-concept [31]. Thus, if a firm conducts its social responsibility appropriately, its members can have positive PEP, which facilitates their self-esteem and self-concept. Then, the employees experience a sense of pride that they belong to a company that performs socially valuable roles missions [43]. This will result in a higher level of identification of the members with the organization.

Through a social contagion process [44], the enhanced OI of an individual member, which is explained by the aforementioned theoretical mechanisms, tends to be shared among members in an organization [45-47]. Then, the shared positive attitude is likely to be aggregated at collective-level, creating a "common attitudinal ground" [48]. Therefore, as social identity and PEP theory proposed, the shared positive self-concept and perception of support formed by CSR, enhance collective OI among members. Thus, we propose the following Hypothesis:

Hypothesis 1. CSR is positively associated with OI.

\subsection{OI and Organizational Performance}

OI has occupied a central position in organizational behavior literature in that it constitutes a fundamental subtext in which attitudes and behaviors of members in organization are developed $[46,47,49,50]$. Many studies have reported that OI significantly influences not only an employee's 
work attitudes such as job satisfaction and affective organizational commitment $[29,30]$, but also behaviors of members including cooperative behavior, in-role, and extra-role behaviors [26,31,32,43].

Through a social contagion process [44], the enhanced OI of an individual member, which is explained by the aforementioned theoretical mechanisms, tends to be shared among members in an organization [45-47]. Then, it contributes to critically increasing collective-level performance, such as financial performance $[23,33,34]$. Thus, we propose the following Hypothesis:

Hypothesis 2. OI is positively associated with organizational performance.

\subsection{Mediating Role of OI between CSR and Organizational Performance}

By integrating the above hypotheses that explain direct associations among CSR, OI, and organizational performance, we propose that OI mediates the link between CSR and organizational performance. The mediation model is theoretically based on institutional theory [25]. The theory suggests that institutional enablers such as CSR practices, critically influence perceptions, attitudes (i.e., OI), then significantly predicting organizational performance. According to the theory, institutional enablers such as organizational practices or systems critically affect macro-level outcomes by building micro-level intermediating processes, such as employee's perceptions, attitudes, and behaviors. Based on the institutional theory, we propose that CSR may play a role of institutional enabler which indirectly influences organizational performance via micro-level intermediating mechanisms such as employee' attitudes or behaviors.

In this present study, we expect that OI plays a critical mediating role in the link between CSR and organizational performance. Existing research have demonstrated that $\mathrm{OI}$ is a primary consequence of CSR, although at the individual-level [21,22,51]. Moreover, other micro-level studies on OI revealed that it significantly predicts performance $[23,33,34]$. In that the social contagion process tends to share the individual-level phenomena among members in an organization [44-47], the relationship among the variables at the individual level would be established at the collective level. Therefore, based on the theoretical framework of institutional approach, we can infer that the level OI would function as an intermediate attitudinal mechanism in the link between CSR and performance.

Hypothesis 3. OI mediates the relationship between CSR and organizational performance.

\subsection{Moderating Effects of Authentic Leadership in CSR-OI Relationship}

We suggest that the authenticity of leadership would play a contingent role in the association between CSR and OI. To demonstrate it, we develop systematic reasoning on the relationships among leadership, CSR, and authenticity.

\subsubsection{Leadership and Authenticity of CSR}

Although there would be various factors which are pertinent to the authenticity of CSR, in the present study, we focus on the members' perception on it. Specifically, we delve into the function of leadership because not only leadership crucially affects the organizational life by shaping employee's attitudes and behaviors [52], but also leader is perceived as a Figure who represents the organization [36]. Thus, we suggest that members may consider authenticity of leadership as an indicator to judge whether their organization's CSR is authentic.

Organizational members often anthropomorphize their organizations [53]. This means that members recognize their organization, which is a virtual and invisible entity, as one "human", endowing it with humanlike qualities such as motives and intentions [54,55]. In addition, they view their leader as a Figure who represents the organization [36]. Thus, the members are highly likely to perceive that their leader is a symbolic actor of their organization, meaning that they tend to perceive 
the acts of their leaders as the very ones of their organization. As a result, it is very likely that members will consider the authenticity of their leader as a criterion to judge whether CSR practice by the firm is authentic, based on the unique values and philosophy of the firm $[35,56]$. If a leader does not behave with authenticity even though the firm has faithfully fulfilled CSR, the members would perceive such CSR practice as an act that has "another hidden purpose". This causes them to doubt the authenticity of CSR practices, which will decrease the positive effects of CSR in an organization. Specifically, the enhancing effect of CSR on OI will be decreased when the degree of leader's authenticity is low.

\subsubsection{AL's Moderating Role in the Link between CSR and OI}

More specifically, to investigate the authenticity of leader, we focus on AL which is defined as a transparent and balanced decision-making pattern, based on a leader's internalized moral standards $[35,56]$. The moderating effect of AL on the relationship between CSR and OI can be specified based on the sub-components of AL, self-awareness, internalized moral perspective, relational transparency, and balanced information processing. Conceptually, the four factors can be categorized into two groups in that the former two factors are associated with how to build the authenticity, while the latter two are related to how to express it.

First, leader's self-awareness and internalized moral perspective, which function as sources to create authenticity of them, may play a role of a moderator to amplify or diminish the positive effect of CSR on OI. Self-awareness refers to how aware a leader is of his or her values, philosophy, outlook on the world, strengths and weaknesses, others' evaluation of him or her, and the impact that he or she has on others $[35,57,58]$. In addition, internalized moral perspective means whether a leader not only has ethical and moral standards that he or she has formed through the self-awareness, but also makes "consistent" decisions and behaviors based on his or her internalized value [35,59]. When the degree of self-awareness of leader is high, members would perceive that their organization not only is aware of its own value systems but also its decision making or strategies pertinent to CSR are based on its own philosophy. In addition, from the viewpoint of members, the internalized morality of their leader may be interpreted as the one of their organization. If they believe that their organization's CSR activities originate in its immanent morality through self-awareness, the members would perceive that the CSR of their organization is authentic. Through the members' perception of authenticity, the positive effect of CSR on OI would be amplified. On the contrary, the enhancing influence of CSR would be eroded when they feel that the CSR is not authentic.

Next, relational transparency and balanced information processing, which are pertinent to the methods of conveying the authenticity, are likely to function as a contingent factor in the link between CSR and OI. Relational transparency is the extent of how a leader treats others based on his or her authentic self. The leader expresses his or her thoughts and emotions, providing information in a reliable way. The leader also provides an opportunity to the members to freely express their thoughts and opinions as they are [35,58]. In addition, balanced information processing refers to whether a leader objectively analyzes related information before making a decision, and whether the leader requests the employees to question and challenge his or her own opinions [35,59]. The relational transparency and balanced information processing is associated with the "process" of implementing CSR. Although an organization implements CSR practices actively, if the process of implementation is not transparent or balanced, members would doubt the authenticity of CSR practices. In that case, the increasing effect of CSR on OI would be weakened. In other words, the positive effect of CSR on the members' OI will be positively moderated by AL.

Hypothesis 4. AL will positively moderate the relationship between CSR and OI.

In summary, we propose that CSR improves organizational performance via mediation of OI. In addition, AL moderates the relationship between CSR and OI. The research model is shown in Figure 1. 


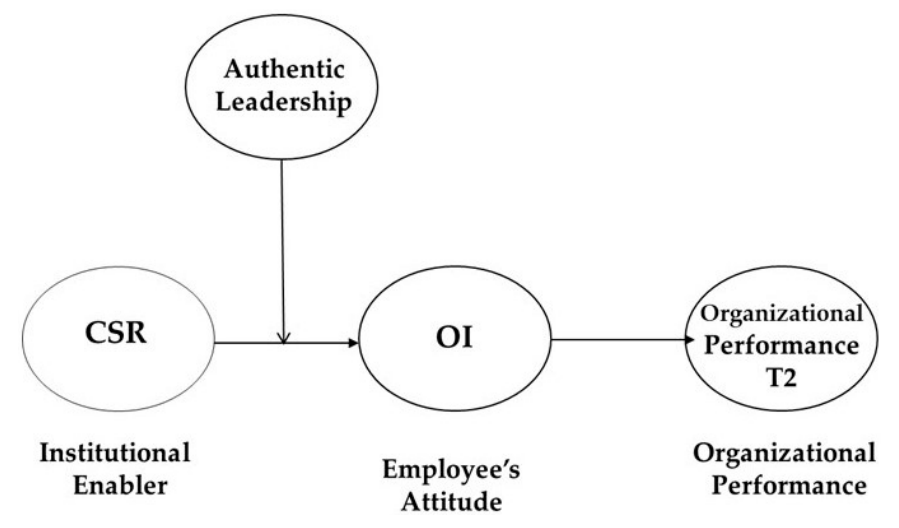

Figure 1. Framework of our research model.

\section{Method}

\subsection{Data Collection}

A total of 512 currently working Korean employees were participated in our survey at Time 1. In addition, at Time 2, 378 employees responded to our second survey following the first survey. Then we eliminated missing data. Finally, we could utilize data from 301 employees. The overall responding rate is $58.79 \%$. Participants were recruited through an online survey pool and were compensated with small amount of money. They are affiliated with different firms including large, medium, and small size corporations. To avoid the limitations of cross-sectional data, we obtained our data at two different time points. According to the suggestion of previous studies [60,61], Time 2 was apart from Time 1 by a lag of 4 weeks.

The sample included 154 (51.2\%) men and 147 (48.8\%) women. Participants reported their age as follows: $20 \mathrm{~s}(22.6 \%), 30 \mathrm{~s}(26.6 \%), 40 \mathrm{~s}(26.2 \%)$, and $50 \mathrm{~s}(24.6 \%)$. The occupational types of respondents were office workers $(62.5 \%)$, administrative positions (20.3\%), manufacturing worker (5.3\%), sales and marketing $(3.3 \%)$, and education (1.7\%). Pertinent to their positions, staff $(31.2 \%)$, assistant manager $(25.9 \%)$, manager or deputy general manager $(27.6 \%)$, department/general manager and above director $(15.3 \%)$ were included. Participants indicated their industry as follows: manufacturing $(25.2 \%)$, construction and real estate $(15.6 \%)$, service $(13 \%)$, information service and telecommunications $(10 \%)$, education $(9.3 \%)$, health and welfare $(7.6 \%)$, public service and administration $(7.3 \%)$, and financial and insurance activities (3.7\%). In addition, pertinent to firm size the participants belong to, there are firms having above 500 employees (18.3\%), 300-499 employees (7\%), 100-299 employees (15.9\%), $50-99$ employees (12.6\%), and below 50 employees (46.2\%). Finally, regarding tenure, below 50 months (52.2\%), 50 to 100 months (19.2\%), 100 to 150 months (14.3\%), 150 to 200 months (5\%), 200 to 250 months $(5 \%)$, and above $250(5.3 \%)$ were included.

\subsection{Measures}

All research variables were measured by multi-item scales with a five-point Likert scale ( $1=$ strongly disagree, $5=$ strongly agree). We calculated internal consistency of all variables using Cronbach alpha coefficients.

\subsubsection{CSR (Time Point 1 )}

To measure CSR in organizations, we used 12 items (Cronbach alpha $=0.90)$ modifying Turker's CSR scale [62] to fit the purpose of our research. The scale was based on the stakeholder approach which consists of questionnaires about the social responsibility towards various stakeholders. Since it was not practically possible to include all the stakeholders [62], four domains of them were selected to represent the whole CSR construct. As a result, environment, community, employee, and customer 
dimension were selected. For measuring environment domain, three items were utilized. Sample item is "our company participates in activities which aim to protect and improve the quality of the natural environment". The community domain also includes three items. Sample item is "our company contributes to campaigns and projects that promote the well-being of the society". The employee domain included three questions. Sample item is "The management of our company is primarily concerned with employees' needs and wants". Lastly, three items on customer domain were used: "our company respects consumer rights beyond the legal requirements". These items were collected at first time point.

To examine whether our CSR measure has four components as we described, we conducted a confirmatory factor analysis (CFA) using AMOS. To find a best-fitted model, we sequentially compared the fit indices of the four-factor model with a three-factor model, a two-factor model, and a one-factor model, sequentially conducting chi-square difference tests. As Hu and Bentler [63] recommended, models with good fit should have a comparative fit index (CFI) and Tucker-Lewis index (TLI) of 0.90 or greater and a root mean square error of approximation (RMSEA) of less than or equal to 0.06 . In our study, all measured items loaded significantly on their latent factors in all four tested models. However, the four-factor model $(\chi 2(\mathrm{df}=43)=78.406$; $\mathrm{CFI}=0.98 ; \mathrm{TLI}=0.97$; RMSEA $=0.052)$ outperformed the three-factor, two-factor, and one-factor model.

\subsubsection{Authentic Leadership (Time Point 1)}

To measure the level of $\mathrm{AL}$, we used four items (Cronbach alpha $=0.86$ ) of Authentic Leadership Questionnaire (ALQ) developed by Walumbwa and his colleagues [35]. ALQ consists of four dimensions: (1) self-awareness (e.g., "The leader knows when it is time to re-evaluate his or her positions on important issues"), (2) relational transparency (e.g., "The leader says exactly what he or she means"), (3) internalized moral perspective (e.g., "The leader makes difficult decisions based on high standards of ethical conduct"), and (4) balanced processing (e.g., "The leader listens carefully to different points of view before coming to conclusions"). ALQ is a valid scale as confirmed by previous studies [64-66]. We collected the data at first time point.

\subsubsection{OI (Time Point 2)}

At time point 2, four items for OI were selected from the scale of Mael and Ashforth [31]. According to the suggestion of previous research [67], we selected core items of the OI scale. Sample items were "it is as if I were insulted if someone criticizes the company I work for"; "my company's success ultimately means my own success"; and "I usually say 'our company' when talking about my company". The value of Cronbach alpha in this study was $=0.77$.

\subsubsection{Organizational Performance (Time Point 2, Collected from HRM Director of Each Firm)}

At time 2, to measure organizational performance, we utilized the evaluations of human resource management (HRM) director of each company. The measure consists of three items. Sample item are "our company is more efficient and productive than our competitors"; "our management performance is superior to our competitors"; "our financial performance is excellent compared to our competitors. This multi-source measure may diminish the problems of common method bias. The value of Cronbach alpha in this study was $=0.91$.

\subsubsection{Control Variables (Time Point 2)}

To minimize biased estimates, we controlled various variables for organizational performance and OI. According to the suggestion of previous studies [68,69], firm size and industry characteristics are critical firm-specific factors which affects various organizational outcomes. Thus, in this research, firm size and industry type were included to control for organizational performance. In addition, tenure, gender, position, and education level were included to control for OI $[66,70]$. These control variables were collected at time 2 . 


\subsection{Data Analysis}

We conducted a correlation analysis to obtain basic insight of our data. Then we assessed the fit indices of our hypothesized moderated mediation model using SEM. The SEM is an optimal tool to test multivariate models, such as mediation analysis [71]. It can verify latent variables with multiple indicators, adequately controlling for measurement errors. Therefore, SEM has a strong point to deal with the issue of underestimating mediation effects. In our research, we took a two-step approach consisting of measurement model and structural model tests according to the suggestion of Anderson and Gerbing [72]. Model fit was assessed by a variety of goodness-of-fit indices, such as chi-square ( $\chi 2$ ), CFI, TLI, and RMSEA that are commonly recommended in the existing studies [63]. Desirable model fit is related to a CFI and a TLI greater than 0.90 and a RMSEA less than or equal to 0.06 [63].

In addition, we compared our hypothesized model to a nested alternative model to find best model which fits the data through chi-square difference test [73]. The fit of the structural models was evaluated by goodness-of-fit indices such as $\chi 2$, CFI, TLI, and RMSEA.

After testing the measurement and structural models, we examined the mediation effect of OI between CSR and organizational performance conducting a bootstrapping method [74]. Moreover, to verify the moderating effect of AL on the relationship between CSR and OI, we used a moderated mediation model that integrates moderation with mediation using SEM [75].

\section{Results}

\subsection{Descriptive Statistics}

Pearson correlation analysis was performed to examine the correlations among the research variables, and the results are shown in Table 1. Based on the results, we investigate the relationship among the variables within an integrative and comprehensive structure by using SEM. The means, standard deviations, and correlation coefficients among our research variables are also shown in Table 1.

Table 1. Means, Standard Deviations, and Inter-Correlations of Measures.

\begin{tabular}{|c|c|c|c|c|c|c|c|c|c|c|c|}
\hline & Mean & SD & 1 & 2 & 3 & 4 & 5 & 6 & 7 & 8 & 9 \\
\hline 1. Gender & 1.49 & 0.50 & - & & & & & & & & \\
\hline 2. Position & 2.49 & 1.39 & $-0.37 * *$ & - & & & & & & & \\
\hline $\begin{array}{l}\text { 3. Tenure } \\
\text { (Months) }\end{array}$ & 79.18 & 81.28 & -0.06 & $0.34^{* *}$ & - & & & & & & \\
\hline 4. Education & 2.56 & 0.84 & -0.11 & $0.16^{* *}$ & -0.02 & - & & & & & \\
\hline 5. Firm size & 2.39 & 1.55 & $-0.13 *$ & -0.01 & $0.22 * *$ & $0.18^{* *}$ & - & & & & \\
\hline 6. Industry type & & & $0.23 * *$ & 0.01 & 0.05 & 0.08 & -0.10 & - & & & \\
\hline 7. CSR & 3.25 & 0.62 & -0.11 & 0.10 & $0.13 *$ & 0.07 & $0.29^{* *}$ & 0.04 & - & & \\
\hline 8. AL & 3.21 & 0.71 & -0.01 & 0.01 & 0.07 & -0.01 & 0.11 & 0.06 & $0.53^{* *}$ & - & \\
\hline 9. OI & 3.35 & 0.65 & 0.04 & $0.12 *$ & 0.08 & -0.01 & 0.07 & $0.09^{-}$ & $0.33^{* *}$ & $0.32 * *$ & - \\
\hline 10. Performance & 2.95 & 0.77 & -0.06 & 0.05 & 0.04 & -0.11 & 0.00 & 0.02 & $0.40 * *$ & $0.36^{* *}$ & $0.55^{* *}$ \\
\hline
\end{tabular}

${ }^{*} p<0.05$. ${ }^{* *} p<0.01$. As for gender, males are coded as 1 and females as 2 . As for position, general manager or higher are coded as 5 , deputy general manager and department manager 4 , assistant manager 3 , clerk 2 , and others below clerk as 1 . As for education, "below high school diploma" level is coded as 1, "community college" level as 2, "bachelor's" level as 3, and "master's degree or more" level is coded as 5.

\subsection{Measurement Model}

To test a measurement model, we performed confirmatory factor analyses (CFA) to examine whether the measurement model exhibited an acceptable fit to the data. To identify discriminant validity of our three psychometric scales (i.e., CSR, AL, and OI), CFA of all 20 items which compose all scales was conducted. According to the result of above CFA for CSR measure, the CSR scale has four sub-dimensions. Thus, we included the four sub-factors of CSR in this measurement model. The three-factor model demonstrated a very good fit to the observed data $\left(\chi^{2}(\mathrm{df}=48)=85.61\right.$; $\mathrm{CFI}=0.975 ; \mathrm{TLI}=0.966$; RMSEA $=0.051$ ). We sequentially compared the three-factor model to two-factor and single-factor models, sequentially conducting chi-square difference tests. The results of 
the chi-square difference tests indicated that the three-factor model fits the data best among all the alternative models, implying the distinctiveness of our three variables.

\subsection{Structural Model}

\subsubsection{Result of Moderation Analysis}

We established a structural equation model that comprehensively describe the association among our study variables. The model includes both a mediating structure that led to CSR $\rightarrow$ OI $\rightarrow$ organizational performance and a moderation structure that suggests AL moderates the relationship between CSR and OI. To test the model, we needed a "moderated mediation model" that combined the mediating model with a moderating model at the same time. To test the moderation effect, we calculated interaction terms by multiplying perceived CSR and AL. In addition, we centered the variables on their means to decrease the multicollinearity that may exist. Centered variables enhance the ability to estimate the interaction term without influencing the correlations among the variables. Also, we checked the multicollinearity bias among the independent variables, such as CSR and AL. The multicollinearity bias not only decreased the predictability of the regression model but also causes problems when estimating the relative contribution of each predictor [76]. Using SPSS, we calculated the variance inflation factor (VIF) and tolerance to detect whether CSR and AL had this problem [76]. The VIF values for CSR and AL were both 1.38 and 1.38, being much lower than 10, and the tolerance statistics were both 0.72 and 0.72 , well above 0.2 , meaning that the two variables were free from bias. Finally, the significance of the path coefficient from the interaction term to OI was examined.

Then, to empirically test our theoretical framework, we conducted a series of SEM analyses. To find a best model that fits to the data, we compared fit indices between the hypothetical model and alternative nested model, conducting chi-square difference test. First, we tested our full mediation model (Model 1) using SEM. The fit indices of the full mediation model were enough to accept $(\chi 2=176.279(\mathrm{df}=122) ; \mathrm{CFI}=0.972 ; \mathrm{TLI}=0.960 ;$ RMSEA = 0.039). Next, we compared Model 1 with an alternative nested model, partial mediation model (Model 2). Model 2 is identical to Model 1 except for the addition of one path (the path from CSR to organizational performance). Model 2 also showed very good fit $(\chi 2=155.383(\mathrm{df}=121) ; \mathrm{CFI}=0.982 ; \mathrm{TLI}=0.975 ; \mathrm{RMSEA}=0.031)$. To compare the models, we conducted chi-square difference test. The result of it demonstrated that the fit of Model 2 was better than Model $2(\Delta \times 2[1]=20.896, p<0.001)$. The results indicate that the partial mediation model has better fit, ruling out the full mediation mechanism.

Results of the best-fitting hypothesized model are presented in Figure 2. Among our control variables (tenure, position, firm size, gender, and industry type), gender, position, and firm size were statistically significant. After controlling for its indirect effects through OI, CSR did significantly predict organizational performance. The result showed that CSR was positively related to OI ( $\beta=0.29$, $p<0.01$ ), confirming Hypothesis 1 . Hypothesis 2 was also supported because OI was significantly associated with organizational performance $(\beta=0.52, p<0.001)$.

\subsubsection{Result of Moderation Analysis}

To test the moderating effect of AL on the relationship between CSR and OI, we established a moderated mediation model that combines moderation with mediation (see Figure 3). To form the interaction term between the AL and CSR, the two variables were mean-centered and multiplied [75]. If the coefficient of path from the interaction term to the OI is significant, we can interpret that there exists moderation effect of AL between CSR and OI [75].

The coefficient value of the interaction term $(\beta=0.31, p<0.001)$ presented that the AL functions as a moderator between CSR and OI. The result indicates that the relationship between CSR and OI was stronger when the level of AL was high than when it was low. Thus, we can conclude that Hypothesis 4 was supported. 


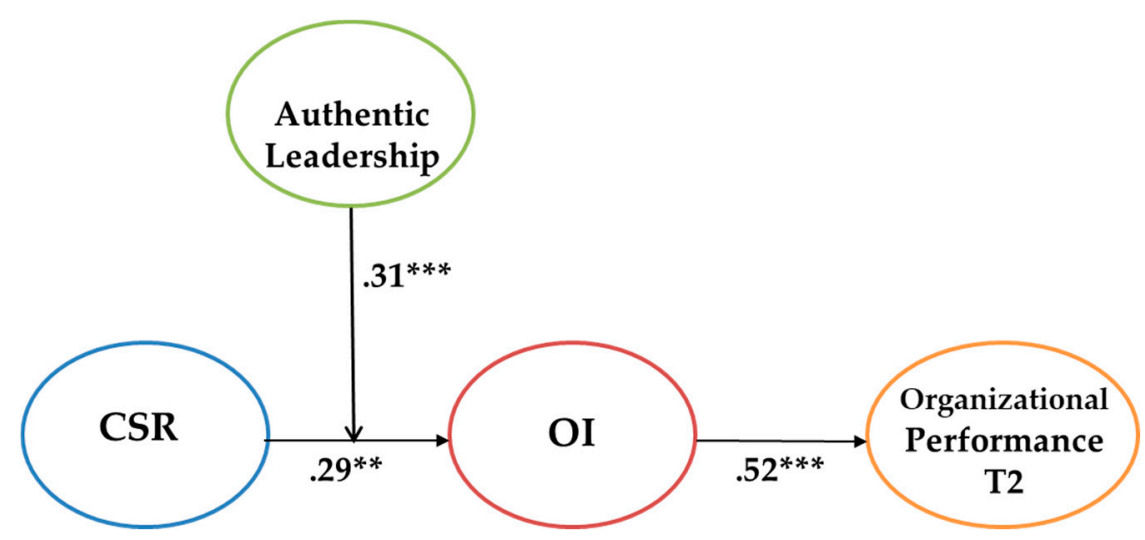

Figure 2. Final structural model. Standardized coefficients are presented. ${ }^{*} p<0.05,{ }^{* *} p<0.01$, $* * * p<0.001$.

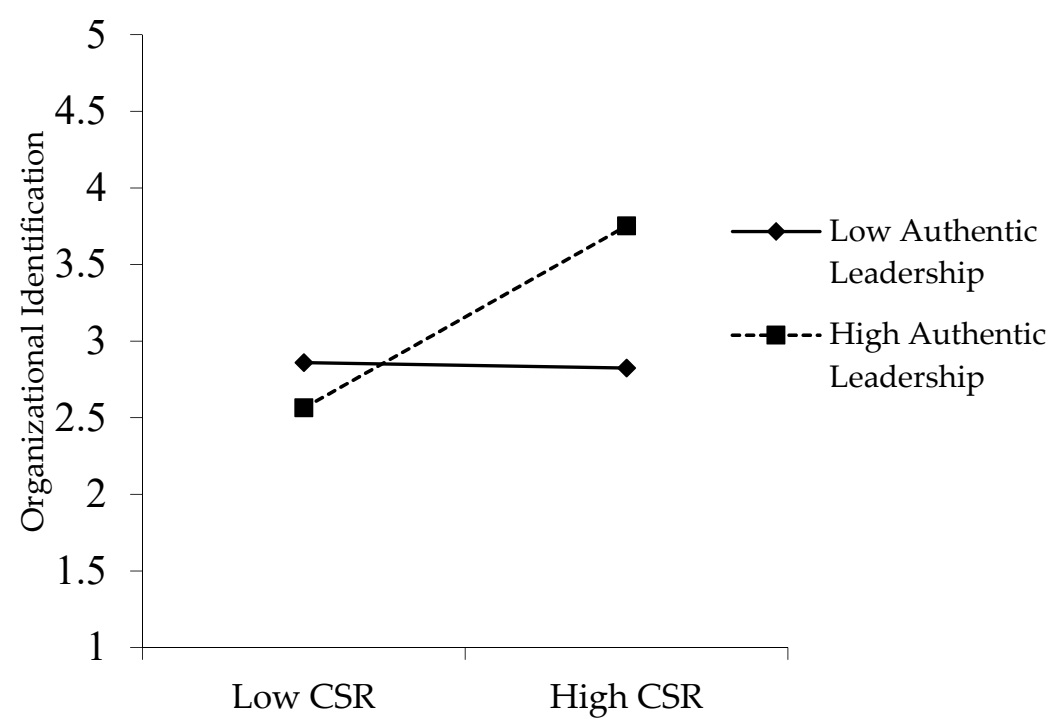

Figure 3. Moderating effect of AL in the CSR-OI link.

\subsection{Bootstrapping}

To test Hypothesis 3 which proposed that OI mediates the effect of CSR on organizational performance, we conducted bootstrapping procedures using a sample of 5000 [71]. We reported the $95 \%$ bias-corrected confidence interval (CI) for the mean indirect mediation effect. If the CI does not include zero, the indirect effect is significant at the 0.05 level [74]. The $\mathrm{CI}$ for the mean indirect effect of CSR on organizational performance through OI excluded zero $(95 \% \mathrm{CI}=[0.09,0.43])$. The result demonstrates that the mediation effect of OI between CSR and organizational performance was statistically significant, thus confirming Hypothesis 3.

\section{Discussion and Conclusions}

Although the studies on CSR have been conducted continuously, there has been relatively little research on internal processes between CSR and organizational performance [2]. Extant studies investigating the influence of CSR has mainly focused on externally-oriented perspectives at the macro-level, considering a simple bivariate linear association between CSR and organizational performance $[77,78]$. To complement the limitations of previous research, we focus on CSR's internal process and contingent factor to describe the relationship between CSR and organizational performance. From our empirical analysis with two-wave time-lagged data, we found that OI plays a critical role 
of mediator between CSR and organizational performance. In addition, authenticity of leader is an important conditional or contingent factor that moderates the influence of CSR on OI. In this section, we will describe the theoretical and practical implications of this study, as well as its limitations and suggestions for future works.

\subsection{Theoretical Implications}

This research has following theoretical implications. First, we attempted to provide internallyoriented perspective, combining a macro- and micro-level approach. Grounded on institutional theory [25], we suggest the influence of macro-level phenomena (i.e., CSR practices and organizational performance) can be unfolded through micro-level mechanisms, such as attitudes of employees [79]. The results bolstered our hypotheses, demonstrating the mediating role of $\mathrm{OI}$ as an internal mechanism in the link between CSR and performance. By focusing on the internal process between macro variables beyond the existing externally-oriented approach, we provided the possibility of integration between macro- and micro-level dynamics. In addition, to connect the two perspectives, we draw on the institutional approach as a guiding theory by interpreting micro theories (i.e., social identity theory and authentic leadership theory) in the perspective of institutional theory. Our efforts would contribute to emphasizing the significance of micro-foundations of CSR.

Second, our research demonstrated the importance of "authenticity" which is revealed by leadership in an organization. No matter how actively a firm implements CSR practices, the positive effect of CSR on member's attitudes would decrease if there is a lack of "authenticity" in such good acts. What is as essential for a good act is what attitude and mindset such an act is performed. Considering the powerful role of leaders in an organization, their authenticity cannot be emphasized enough. These findings imply that the authenticity of leaders should be critically considered to fully achieve the positive effects of CSR on member's attitudes. For leaders or top management teams who intend to maximize or to not impair the positive effect of CSR, it is crucial to properly manage the authenticity of leaders. At the same time, top management team should develop the organizational culture which emphasizes the significance of authenticity.

\subsection{Practical Implications}

Our results may supply practical suggestions for leaders or top management teams of companies who attempt to maximize their performance through CSR activities. First, based on our results, the leaders may get important insight which suggests CSR may be a substantial "investment" rather than an "obligation" that companies must perform. If an organization actively and sincerely implements CSR practices, employees may feel more dedication and attachment to their firms. Considering that the employees' perceptions and work attitudes have a critical impact on the performance of firms, enhancing the quality of the perceptions and attitudes of employees through CSR may be a reasonable choice which is worth investing in. Thus, top management teams need to not only acknowledge the ideological and practical values of CSR, but also build a CSR-oriented culture.

Second, our result showed that the positive influence of CSR on organizational performance works only via attitudes of members such as OI. Employees, as a significant internal stakeholder, would transform the organization-level moral endeavors into economic outcomes. By interpreting and implementing the CSR practices, they realize the moral efforts in the form of practical outcomes. Top management teams of leaders should consider their employee as an important agent to maximize the positive effect of CSR practices. Thus, we recommend the management teams not only to communicate with them regularly about the CSR activities, but also provide appropriate rewards. It would contribute to building a CSR-culture in an organization $[24,80]$.

Lastly, top management teams or leaders should recognize the importance of authenticity which would be revealed by AL. The positive impacts of CSR practices on members' attitudes such as OI may be offset if the level of AL is low. The increasing effect of CSR on OI would be maximized when the CSR is on the solid ground of authenticity which is reflected by leadership. Although an organization 
actively implements CSR activities, if the organization has not cultivated AL, members are less likely to experience OI. It means that AL critically influences the positive impact of CSR practices on member's attitudes. For members in an organization, AL may function as an indicator to judge whether their organizational policies or practices pertinent to CSR are genuine. Therefore, top management teams or leaders should not only acknowledge the significance of $\mathrm{AL}$, but also substantially endeavor to cultivate the AL.

\subsection{Study Limitations and Directions for Future Research}

Despite the aforementioned strong points, the present study has limitations which need to be dealt with in future works. First, although the core value of CSR activities may be common in both Western and Eastern community [24,81], there may exist cultural difference in the employees' interpretation about CSR. Since this research only gathered data from companies in South Korea, it is not possible to eliminate the possibility of cultural influences. Therefore, we must cautiously interpret our results to explain the CSR-related phenomena in different cultures $[24,82,83]$. Since Korea has experienced dramatic economic growth during last centuries, employees in Korean firms may be relatively less sensitive to the moral activities (i.e., CSR practices) compared to employees in Western firms [24,84].

Second, due to various practical restraints in gathering data, this study only utilized partial items to measure AL and OI. Even though the items included in the present research adequately measure the core domains of our research variables, the shorted scales would diminish the overall validity of the construct. Future works should consider and complement this limitation.

Lastly, our research could not include other measures for CSR such as objective indices or content analysis of various documents. As though existing research argues that the perceptions of employees about CSR would reflect more accurately the phenomena of CSR than CSR activities themselves [85], it is possible that objective measures are likely to show different associations with our study variables. Therefore, using CSR scales in a comprehensive way is recommended in future studies.

Although this research has some limitations, we expect that we can contribute to CSR literature by providing theoretical and empirical implications on internal intermediating process of CSR. This research may enrich the micro-foundations of CSR literature through revealing an important mediator (i.e., OI) and moderator (i.e., AL) to explain the CSR-performance link.

Author Contributions: B.-J.K., T.-H.K., and T.K. author equally contributed in writing original draft, conceptualization, data collection, formal analysis, and methodology. M.N. contributed in analysis, review and edit the paper.

Funding: This research received no external funding.

Conflicts of Interest: The authors declare no conflict of interest.

\section{References}

1. Aguilera, R.V.; Rupp, D.E.; Williams, C.A.; Ganapathi, J. Putting the S back in corporate social responsibility, A multilevel theory of social change in organizations. Acad. Manag. Rev. 2007, 32, 836-863. [CrossRef]

2. Aguinis, H.; Glavas, A. What we know and don't know about corporate social responsibility: A review and research agenda. J. Manag. 2012, 38, 932-968. [CrossRef]

3. Müller, K.; Hattrup, K.; Spiess, S.-O.; Lin-Hi, N. The effects of corporate social responsibility on employees' affective commitment: A cross-cultural investigation. J. Appl. Psychol. 2012, 97, 1186-1200. [CrossRef] [PubMed]

4. Friedman, M. The social responsibility of business is to increase its profits. New York Times Magazine, 13 September 1970, p. 17.

5. Lopez, M.; Garcia, A.; Rodriguez, L. Sustainable development and corporate performance: A study based on the Dow Jones Sustainability Index. J. Bus. Ethics 2007, 75, 285-300. [CrossRef]

6. Waddock, S.A.; Graves, S.B. The corporate social performance-financial performance link. Strateg. Manag. J. 1997, 18, 303-319. [CrossRef] 
7. Orlitzky, M.; Benjamin, J.D. Corporate social performance and firm risk: A meta-analytic review. Bus. Soc. 2001, 40, 369-396. [CrossRef]

8. Peloza, J. The challenge of measuring financial impacts from investments in corporate social performance. J. Manag. 2009, 35, 1518-1541. [CrossRef]

9. Van Beurden, P.; Gossling, T. The worth of values-A literature review on the relation between corporate social and financial performance. J. Bus. Ethics 2008, 82, 407-424. [CrossRef]

10. Lai, C.S.; Chiu, C.J.; Yang, C.F.; Pai, D.P. The Effects of Corporate Social Responsibility on Brand Performance: The Mediating Effect of Industrial Brand Equity and Corporate Reputation. J. Bus. Ethics 2010, 95, 457-469. [CrossRef]

11. Lee, M.; Kim, H. Exploring the Organizational Culture's Moderating Role of Effects of Corporate Social Responsibility (CSR) on Firm Performance: Focused on Corporate Contributions in Korea. Sustainability 2017, 9, 1883. [CrossRef]

12. Shin, I.; Hur, W.-M.; Kang, S. Employees' Perceptions of Corporate Social Responsibility and Job Performance: A Sequential Mediation Model. Sustainability 2016, 8, 493. [CrossRef]

13. Kim, M.-S.; Thapa, B. Relationship of Ethical Leadership, Corporate Social Responsibility and Organizational Performance. Sustainability 2018, 10, 447.

14. McGuire, J.B.; Sundgren, A.; Schneeweis, T. Corporate social responsibility and firm financial performance. Acad. Manag. J. 1988, 31, 854-872.

15. Saeidi, S.P.; Sofian, S.; Saeidi, P.; Saeidi, S.P.; Saaeidi, S.A. How does corporate social responsibility contribute to firm financial performance? The mediating role of competitive advantage, reputation, and customer satisfaction. J. Bus. Res. 2015, 68, 341-350. [CrossRef]

16. Aupperle, K.E.; Carroll, A.B.; Hatfield, J.D. An empirical examination of the relationship between corporate social responsibility and profitability. Acad. Manag. J. 1985, 28, 446-463.

17. McWilliams, A.; Siegel, D. Corporate social responsibility and financial performance: Correlation or misspecification? Strateg. Manag. J. 2000, 21, 603-609. [CrossRef]

18. Peng, C.W.; Yang, M.L. The Effect of Corporate Social Performance on Financial Performance: The Moderating Effect of Ownership Concentration. J. Bus. Ethics 2014, 123, 171-182. [CrossRef]

19. Lin, C.; Chen, S.; Chiu, C.; Lee, W. Understanding purchasing intention during product harm crises: Moderating effects of perceived corporate ability and corporate social responsibility. J. Bus. Ethics 2011, 102, 455-471. [CrossRef]

20. Rupp, D.E.; Mallory, D.B. Corporate social responsibility: Psychological, person-centric, and progressing. Annu. Rev. Organ. Psychol. Organ. Behav. 2015, 2, 211-236. [CrossRef]

21. Carmeli, A.; Gilat, G.; Waldman, D.A. The role of perceived organizational performance in organizational identification, adjustment and job performance. J. Manag. Stud. 2007, 44, 972-992. [CrossRef]

22. Farooq, O.; Payaud, M.; Merunka, D.; Valette-Florence, P. The impact of corporate social responsibility on organizational commitment: Exploring multiple mediation mechanisms. J. Bus. Ethics 2014, 125, 563-580. [CrossRef]

23. Harrison, D.A.; Newman, D.A.; Roth, P.L. How important are job attitudes? Meta-analytic comparisons of integrative behavioral outcomes and time sequences. Acad. Manag. J. 2006, 49, 305-325. [CrossRef]

24. Chun, J.S.; Shin, Y.; Choi, J.N.; Kim, M.S. How does corporate ethics contribute to firm financial performance? The role of collective organizational commitment and organizational citizenship behavior. J. Manag. 2013, 39, 853-877.

25. Scott, W.R. Institutions and Organizations; Sage: Thousand Oaks, CA, USA, 1995.

26. Ashforth, B.E.; Mael, F. Social identity theory and the organization. Acad. Manag. Rev. 1989, 14, 20-39. [CrossRef]

27. Kreiner, G.E.; Ashforth, B.E. Evidence toward an expanded model of organizational identification. J. Organ. Behav. 2004, 25, 1-27. [CrossRef]

28. Van Dick, R. My job is my castle: Identification in organizational contexts. In International Review of Industrial and Organizational Psychology; Cooper, C.L., Robertson, I.T., Eds.; Wiley: Chichester, UK, 2004; pp. 171-203.

29. Meyer, J.P.; Becker, T.E.; van Dick, R. Social identities and commitments at work: Toward an integrative model. J. Organ. Behav. 2006, 27, 665-683. [CrossRef] 
30. Van Dick, R.; van Knippenberg, D.; Kerschreiter, R.; Hertel, G.; Wieseke, J. Interactive effects of work group and organizational identification on job satisfaction and extra-role behavior. J. Vocat. Behav. 2008, 72, 388-399. [CrossRef]

31. Mael, F.A.; Ashforth, B.E. Alumni and their alma mater: A partial test of the reformulated model of organizational identification. J. Organ. Behav. 1992, 13, 103-123. [CrossRef]

32. Van Dick, R.; Grojean, M.W.; Christ, O.; Wieseke, J. Identity and the extra mile: Relationships between organizational identification and organizational citizenship behaviour. Br. J. Manag. 2006, 17, $283-301$. [CrossRef]

33. Riketta, M. Organizational identification: A meta-analysis. J. Vocat. Behav. 2005, 66, 358-384. [CrossRef]

34. Riketta, M.; Van Dick, R. Foci of attachment in organizations: A meta-analysis comparison of the strength and correlates of work-group versus organizational commitment and identification. J. Vocat. Behav. 2005, 67, 490-510. [CrossRef]

35. Walumbwa, F.O.; Avolio, B.J.; Gardner, W.L.; Wernsing, T.S.; Peterson, S.J. Authentic leadership: Development and analysis of a multidimensional theory-based measure. J. Manag. 2008, 34, 89-126.

36. Schein, E. Organizational Culture and Leadership, 3rd ed.; Jossey-Bass: San Francisco, CA, USA, 2004.

37. Beckman, T.; Colwell, A.; Cunningham, P.H. The emergence of corporate social responsibility in Chile: The importance of authenticity and social networks. J. Bus. Ethics 2009, 86, 191-206. [CrossRef]

38. McShane, L.; Cunningham, P. To Thine Own Self Be True? Employees' Judgments of the Authenticity of Their Organization's Corporate Social Responsibility Program. J. Bus. Ethics 2012, 108, 81-100. [CrossRef]

39. Blackburn, K.; Bose, N.; Haque, M.E. The incidence and persistence of corruption in economic development. J. Econ. Dyn. Control 2006, 30, 2447-2467. [CrossRef]

40. Ashforth, B.E.; Harrison, S.H.; Corley, K.G. Identification in organizations: An examination of four fundamental questions. J. Manag. 2008, 34, 325-374. [CrossRef]

41. Smidts, A.; Pruyn, A.H.; van Riel, C.B.M. The impact of employee communication and perceived external prestige on organizational identification. Acad. Manag. J. 2001, 49, 1051-1062.

42. Pratt, M. To be or not to be: Central questions in organizational identification. In Identity in Organizations: Developing Theory through Conversations; Whetten, D., Godfrey, P., Eds.; Sage: Thousand Oaks, CA, USA, 1998.

43. Dutton, J.E.; Dukerich, J.M.; Harquail, C.V. Organizational images and member identification. Adm. Sci. Q. 1994, 39, 239-263. [CrossRef]

44. Burt, R.S. Social Contagion and Innovation: Cohesion versus Structural Equivalence. Am. J. Sociol. 1987, 92, 1287-1335. [CrossRef]

45. Ostroff, C. The relationship between satisfaction, attitudes, and performance: An organizational level analysis. J. Appl. Psychol. 1992, 77, 963-974. [CrossRef]

46. Pfeffer, J. Organization theory and structural perspectives on management. J. Manag. 1991, 17, 789-803. [CrossRef]

47. Ryan, A.M.; Schmit, M.J.; Johnson, R. Attitudes and effectiveness: Examining relations at the organizational level. Pers. Psychol. 1996, 49, 853-882. [CrossRef]

48. Wright, P.M.; Kehoe, R.R. Organizational-level antecedents and consequences of commitment. In Commitment in Organizations: Accumulated Wisdom and New Directions; Klein, H.J., Becker, T.E., Meyer, J.P., Eds.; Routledge: New York, NY, USA, 2009; pp. 285-307.

49. Hogg, M.A.; Terry, D.J.; White, K.M. A tale of two theories: A critical comparison of identity theory with social identity theory. Soc. Psychol. Q. 1995, 58, 255-269. [CrossRef]

50. Van Knippenberg, D.; van Schie, E.C.M. Foci and correlates of organizational identification. J. Occup. Organ. Psychol. 2000, 73, 137-147. [CrossRef]

51. Kim, H.R.; Lee, M.; Lee, H.T.; Kim, N.M. Corporate social responsibility and employee-company identification. J. Bus. Ethics 2010, 95, 557-569. [CrossRef]

52. Lowe, K.B.; Kroeck, K.G.; Sivasubramaniam, N. Effectiveness correlates of transformation and transactional leadership: A meta-analytic review of the MLQ literature. Leadersh. Q. 1996, 7, 385-425. [CrossRef]

53. Dowling, G.R. Creating Corporate Reputations: Identity, Image and Performance; Oxford University Press: New York, NY, USA, 2001.

54. Hamilton, D.L.; Sherman, S.J. Perceiving persons and groups. Psychol. Rev. 1996, 103, 336-355. [CrossRef] [PubMed] 
55. King, B.G.; Felin, T.; Whetten, D.A. Finding the organization in organizational theory: A meta-theory of the organization as a social actor. Organ. Sci. 2010, 21, 290-305. [CrossRef]

56. Avolio, B.J.; Gardner, W.L.; Walumbwa, F.O.; Luthans, F.; May, D.R. Unlocking the mask: A look at the process by which authentic leaders impact follower attitudes and behaviors. Leadersh. Q. 2004, 15, 801-823. [CrossRef]

57. Kernis, M.H. Toward a conceptualization of optimal self-esteem. Psychol. Inq. 2003, 14, 1-26. [CrossRef]

58. Kernis, M.H.; Goldman, B.M. A multicomponent conceptualization of authenticity: Theory and research. In Advances in Experimental Social Psychology; Zanna, M.P., Ed.; Academic Press: San Diego, CA, USA, 2006; Volume 38, pp. 284-357.

59. Gardner, W.L.; Avolio, B.J.; Luthans, F.; May, D.R.; Walumbwa, F. “Can you see the real me?" A self-based model of authentic leader and follower development. Leadersh. Q. 2005, 16, 343-372. [CrossRef]

60. Andersson, L.M.; Giacalone, R.A.; Jurkiewicz, C.L. On the relationship of hope and gratitude to corporate social responsibility. J. Bus. Ethics 2007, 70, 401-409. [CrossRef]

61. Carmeli, A.; McKay, A.S.; Kaufman, J.C. Emotional intelligence and creativity: The mediating role of generosity and vigor. J. Creat. Behav. 2014, 48, 290-309. [CrossRef]

62. Turker, D. How corporate social responsibility influences organizational commitment. J. Bus. Ethics 2009, 89, 189-204. [CrossRef]

63. Hu, L.; Bentler, P.M. Cutoff criteria for fit indexes in covariance structure analysis: Conventional criteria versus new alternatives. Struct. Equ. Model. 1999, 6, 1-55. [CrossRef]

64. Lyubovnikova, J.; Legood, A.; Turner, N.; Mamakouka, A. How authentic leadership influences team performance: The mediating role of team reflexivity. J. Bus. Ethics 2015. [CrossRef]

65. Peus, C.; Wesche, J.S.; Streicher, B.; Braun, S.; Frey, D. Authentic leadership: An empirical test of its antecedents, consequences, and mediating mechanisms. J. Bus. Ethics 2012, 107, 331-348. [CrossRef]

66. Smith, K.G.; Smith, K.A.; Olian, J.D.; Sims, H.P.; O’Bannon, D.P.; Scully, J.A. Top management team demography and process: The role of social integration and communication. Adm. Sci. Q. 1994, 39, 412-438. [CrossRef]

67. Kim, B.J.; Chang, Y.G.; Kang, J.H.; Kim, T.H. A Contingent Role of Leader Morality in Translating CSR into Organizational Performance: A Multi-level Moderated Mediation Model. In Academy of Management Proceedings; Academy of Management: Atlanta, GA, USA; Volume 2017, p. 12762.

68. Zhang, Y.C.; Li, S.L. High performance work practices and firm performance: Evidence from the pharmaceutical industry in China. Int. J. Hum. Resour. Manag. 2009, 20, 2331-2348. [CrossRef]

69. Greer, C.R.; Ireland, T.C. Organizational and financial correlates of a "contrarian" human resource investment strategy. Acad. Manag. J. 1992, 35, 956-984.

70. Jackson, S.E.; Joshi, A.; Erhardt, N.L. Recent research on teams and organizational diversity: SWOT analysis and implications. J. Manag. 2003, 29, 801-830.

71. Cheung, G.W.; Lau, R.S. Testing mediation and suppression effects of latent variables: Bootstrapping with structural equation models. Organ. Res. Methods 2008, 11, 296-325. [CrossRef]

72. Anderson, J.C.; Gerbing, D.W. Structural equation modeling in practice: A review and recommended two-step approach. Psychol. Bull. 1988, 103, 411-423. [CrossRef]

73. Kelloway, E.K. Using LISREL for Structural Equation Modeling: A Researcher's Guide; Sage: Thousand Oaks, CA, USA, 1998.

74. Shrout, P.E.; Bolger, N. Mediation in experimental and nonexperimental studies: New procedures and recommendations. Psychol. Methods 2002, 7, 422-445. [CrossRef] [PubMed]

75. Hayes, A.F.; Preacher, K.J. Conditional process modeling: Using structural equation modeling to examine contingent causal processes. In Structural Equation Modeling: A Second Course, 2nd ed.; Hancock, G.R., Mueller, R.O., Eds.; Information Age Publishing: Greenwich, CT, USA, 2013.

76. Brace, N.; Kemp, R.; Snelgar, R. SPSS for Psychologists: A Guide to Data Analysis Using SPSS for Windows, 2nd ed.; Palgrave: London, UK, 2003.

77. Luo, X.; Bhattacharya, C.B. Corporate social responsibility, customer satisfaction, and market value. J. Mark. 2006, 70, 1-18. [CrossRef]

78. Roberts, P.W.; Dowling, G.R. Corporate reputation and sustained superior financial performance. Strateg. Manag. J. 2002, 23, 1077-1093. [CrossRef] 
79. Staw, B.M. Dressing up like an organization: When psychological theories can explain organizational action. J. Manag. 1991, 17, 805-819. [CrossRef]

80. Eberle, D.; Berens, G.; Li, T. The impact of interactive corporate social responsibility communication on corporate reputation. J. Bus. Ethics 2013, 118, 731-746. [CrossRef]

81. Eisenbeiss, S.A. Re-thinking ethical leadership: An interdisciplinary integrative approach. Leadersh. Q. 2012, 23, 791-808. [CrossRef]

82. Arnold, D.F.; Bernardi, R.A.; Neidermeyer, P.E.; Schmee, J. The effect of country and culture on perceptions of appropriate ethical actions prescribed by codes of conduct: A Western European perspective among accountants. J. Bus. Ethics 2007, 70, 327-340. [CrossRef]

83. Nisbett, R.E. The Geography of Thought: How Asians and Westerners Think Differently ... and Why; Free Press: New York, NY, USA, 2003.

84. Shin, Y.H.; Sung, S.Y.; Choi, J.N.; Kim, M.S. Top management ethical leadership and firm performance: Mediating role of ethical and procedural justice climate. J. Bus. Ethics 2014, 129, 43-57. [CrossRef]

85. Hansen, S.D.; Dunford, B.B.; Boss, A.D.; Boss, R.W.; Angermeier, I. Corporate social responsibility and the benefits of employee trust: A cross-disciplinary perspective. J. Bus. Ethics 2011, 102, 29-45. [CrossRef]

(C) 2018 by the authors. Licensee MDPI, Basel, Switzerland. This article is an open access article distributed under the terms and conditions of the Creative Commons Attribution (CC BY) license (http://creativecommons.org/licenses/by/4.0/). 